Review Article

\title{
Analysis on the Characteristics of Water Pollution Caused by Underground Mining and Research Progress of Treatment Technology
}

\author{
Xinfeng Wang $\mathbb{D}^{1,2}$ Yuhao Gao, ${ }^{1}$ Xiaojun Jiang $\mathbb{D}^{2,3}$ Qiao Zhang, ${ }^{1}$ and Wengang Liu ${ }^{1}$ \\ ${ }^{1}$ School of Environment and Resources, Xiangtan University, Xiangtan 411105, Hunan, China \\ ${ }^{2}$ Emergency Management Research Center, Xiangtan University, Xiangtan 411105, Hunan, China \\ ${ }^{3}$ School of Public Administration, Xiangtan University, Xiangtan 411105, Hunan, China
}

Correspondence should be addressed to Xinfeng Wang; xfw2020@xtu.edu.cn and Xiaojun Jiang; jiangxiaojun@xtu.edu.cn

Received 16 March 2021; Revised 2 April 2021; Accepted 15 April 2021; Published 19 May 2021

Academic Editor: Hao Wu

Copyright (C) 2021 Xinfeng Wang et al. This is an open access article distributed under the Creative Commons Attribution License, which permits unrestricted use, distribution, and reproduction in any medium, provided the original work is properly cited.

Coal is the primary source of energy in China's energy structure system. With the large-scale mining of mineral resources, a large amount of mine water will be produced in the process of development, construction, and production, which will pollute and damage the ecological environment of mine water. At present, China vigorously advocates coal revolution, implements lowcarbon economy, and carries out clean production of energy development and utilization. Green mining, precision mining, and other strategic ideas have been applied to mine development to guide production practice. This paper does an in-depth analysis of the physical, chemical, biological, and environmental characteristics of mine water, puts forward the basic classification of mine water, and points out the characteristics of environmental hazards of mine water. Aiming at different types of mine water, such as mine wastewater, drainage water, goaf water, mine water with suspended solids, high salinity mine water, acid mine water, and mine water with special pollution, the paper puts forward the mine water treatment and resource utilization technology with different characteristics and strong pertinence. On this basis, the comprehensive treatment and development direction of mine water in the future are prospected.

\section{Introduction}

China is the world's largest producer of coal and a major consumer of coal. China's coal recoverable reserves are the third largest in the world. The coal industry has become an important foundation for the rapid development of the national economy. China's coal situation: in China's natural resources, the basic characteristics are rich coal, poor oil and gas, which determine the important position of coal in primary energy. Compared with oil and natural gas, China's coal reserves are relatively abundant, accounting for $11.60 \%$ of the world's reserves. China's total coal resources are 5.6 trillion tons, of which proven reserves are 1 trillion ton, accounting for $11 \%$ of the world's total reserves. As China's basic energy and industrial raw material, coal has provided a strong guarantee for economic and social development, national energy security, and stable supply for a long time [1-3].

In the process of coal mining, groundwater is exposed to coal seams, rock formations, and human activities, resulting in significant water quality characteristics of the coal industry. Usually containing a large amount of suspended solids, and poor sensory properties, some are highly mineralized or acidic, and even contain radioactive elements and oxides. If they are directly discharged, the formed acidic water will flow into the river or infiltrate into the underground, which will pollute the water source, causing the death of large-scale vegetation. The polluted water will spread to the farmland and easily lead to soil infertility. Declining, silting up the river, and forming serious ecological and social problems, the ecological environment is seriously deteriorated. 
At present, the annual mine water discharge in China is 4.5 billion cubic meters, and the utilization rate is $43.8 \%$, which is far lower than the standard of $80 \%$ in developed countries. Industrial production and mining will lead to a sharp decline in the groundwater level, and there will be leakage areas in the mining area and adjacent cities, which may lead to ground collapse and seawater intrusion [4].

Therefore, in order to ensure the sustainable development of coal resources, it is necessary to take relative measures for the prevention and treatment of polluted water in coal mining. In the process of coal mining, resources cannot be exploited at the expense of massive destruction and waste of water resources. After a series of treatment, the mine water can be reused for production water, urban greening, agricultural irrigation, and drinking water in the mining area, so as to further realize the resource utilization of mine water, optimize the coal production and environment, and rationalize water resources. Development has a virtuous circle.

\section{Characteristics and Classification of Mine Water Pollution}

2.1. Mine Water Characteristics. Mine water is the same as the general groundwater before it is polluted. The lithology and water conservancy conditions of the aquifer determine its water quality characteristics. The $\mathrm{pH}$ of the mine water is mostly neutral to weakly alkaline. If the mineralization is low, the toxic content is generally below the detection limit. In the process of coal mining, when the mine water flows through the coal mining face and the roadway, it is artificially affected. The rock powder, coal powder, and other organic matter are mixed into the water. If the water is polluted, then it is grayish black in color, and contains a large amount of suspended impurities and a certain amount of microorganisms [5].

Mine water in mine production is brought together in various ways, and mining and ore dressing water account for the largest proportion. The main sources of mine wastewater are as follows:

(1) Open-pit mine wastewater: wastewater formed by mining production process; acidic water discharged from waste rock pile after dissolution of waste rock pile after rainfall.

(2) Mine wastewater: mainly production-contaminated groundwater in the process.

(3) Mineral processing waste water: waste water produced in the process of washing, crushing and mineral processing. A large amount of waste water usually contains ore, metal particles, or various mineral processing agents, which are seriously polluted. Wastewater accumulated in the dam.

(4) Other mine wastewater: wastewater from washing vehicles, hospital wastewater, and domestic wastewater, containing solid suspended matter, oil, organic matter, and other pollutants.
2.2. Mine Water Classification. The general principles of mine sewage treatment and reuse are: clean and diversion, sewage and diversion, classification and treatment, and quality and reuse [6]. Mine drainage is divided into three main categories: dewatering water, water in the goaf, and underground sewage in the mine.

Draining water: draining water in coal mines refers to the wastewater that is generated underground due to the formation structure in the coal mining.

Water in the goaf: after long-term mining, the coal mine will easily form a goaf. The goaf needs timely measures. No water will accumulate in these goafs. If no measures are taken, the generated water will be mined. The process creates water hazards and safety issues [7].

Mine underground sewage: in coal mining operations, coal-based aquifers will be naturally drained, and these waters will merge into the bottom of the well to form mine water. Due to the different types of coal, the main pollution characteristics of mine water are also different, mainly divided into: clean mine water, suspended mine water, acidic mine water with acid pollution, high salinity mine water, and special contaminated mine water.

(1) Clean mine water: the quality of clean mine water is good, the $\mathrm{pH}$ is generally neutral, with low turbidity and hardening degree, and toxic and harmful ions are basically not included. This mine water can be intercepted at the water source, discharged to the bottom of the well through the pipeline, and transported to the surface by the pump. This type of water can be used as drinking water after simple disinfection, and water containing beneficial elements can be directly used as mineral water.

(2) Mine water containing suspended solids: in the mining area, mine water containing suspended solids is most common. The $\mathrm{pH}$ is generally neutral, the hardness and salinity are not high, the coal powder is of very small particle size, and rock dust, rock powder, etc., are present. The main component of suspended mineral water is generally black, and the content per liter is about tens to hundreds of milligrams.

(3) High salinity mine water: high salinity mine water generally refers to mine water with a salt content greater than $1000 \mathrm{mg} / \mathrm{L}$. It is also called salt mine water. Groundwater is in contact with carbonate rock and sulfate layer, resulting in $\mathrm{Ca}^{2+}$ in water and an increase in $\mathrm{Mg}^{2+}, \mathrm{Na}^{+}, \mathrm{K}^{+}, \mathrm{SO} 4^{2-}, \mathrm{HCO}^{-}$, and $\mathrm{Cl}^{-}$plasma, so the hardness tends to be high. Such water will be discharged if it is not treated, which will cause the salt content of the river to rise, the soil to grow salinized, and the crops to reduce production.

(4) Acid mine water: acid mine water mainly refers to groundwater with a $\mathrm{pH}$ lower than 6 . It is formed when the groundwater flows through the coal bottom layer of the coal mine, and the pyrite is oxidized to produce sulfurous acid and sulfuric acid under the action of sufficient oxygen and bacteria, resulting in 
the mine water being acidic with a large amount of $\mathrm{SO}^{2-}, \mathrm{Fe}^{2+}, \mathrm{Fe}^{3+}$, and $\mathrm{Mn}^{2+}$ plasma. When the acid mine water is discharged directly without treatment, the water quality will be deteriorated. $\mathrm{Fe}^{2+}$ will consume oxygen in the water, causing the death of a large number of fish, algae, and other organisms. $\mathrm{Fe}^{+}$and $\mathrm{OH}^{-}$combine to form $\mathrm{Fe}(\mathrm{OH}) 3$ reddish brown precipitation, which leads to the red edge of the water. Acid mine water is highly corrosive, and long-term exposure of mine workers to such water can affect their health.

(5) Containing special polluted mine water: mine water containing special pollutants refers to mine water of toxic substances such as fluoride, heavy metals, and radioactive elements. The pollution of such mine water is serious and difficult to handle. Random discharge will damage the ecological environment and affect the utilization of mine water resources.

\subsection{Environmental Hazards of Mine Water. Mine water} classified according to the main pollution characteristics, except for the four types of mine water other than clean mine water, has different levels of pollutants. It corrodes the surface through which the flow passes, and the larger the flow area, the larger the corrosion surface. In addition, the water temperature of groundwater will also be affected by mine water. For example, some large mining areas are affected by mine water, and the hydrological underlying surface of the basin is destroyed, resulting in water-level decline, dry ground cracks, soil erosion, etc. It will further lead to ground collapse, seawater intrusion, and other disasters. Mine water containing pollutants flows into the river. On the one hand, it is difficult to recycle, and it will destroy the ecological balance, pollute the water body, reduce the potential of the farmland near the river to be cultivated, and destroy the vegetation. On the other hand, the base flow is reduced, and the rivers are transformed into seasonal rivers, eventually forming a situation in which the time and space of the basin are unevenly distributed.

Different types of mine water have different environmental hazards.

The suspended solids particles contained in the suspended mineral water are prone to be hydrated with water molecules, which not only forms a hydrated film in the water but also hinders the aggregation of particles, and also keeps the particles in a dispersed state. The interface between the suspended particles is also affected by Brownian motion, which makes the nature of mine water more and more complex.

High-salinity mine water contains high concentrations of inorganic salts. If it is discharged into water bodies without treatment, it will easily lead to an increase in the salinity of surface water and groundwater, affecting the life of river creatures and surrounding residents, causing serious soil salinization, and reducing crop production. At the same time, for nearby factories and living areas, high-salinity mine water purification costs are high. To maintain normal industrial production and domestic water, it is necessary to develop deeper groundwater, resulting in resource abuse and economic development.

Acidic mine water is dissolved in water due to heavy metals such as $\mathrm{Cu}, \mathrm{Zn}, \mathrm{Mn}$, As, $\mathrm{Pb}$, and $\mathrm{Cd}$ in coal mines and surrounding rocks. It is more toxic and more harmful than monomers. Acid mine water can dissolve and erode the surrounding rock, and corrode mine working equipment and drainage pipes. If discharged directly without treatment, it will lead to an increase in the acidity of surface water. If it flows into a highly biological river, it will cause serious damage to the ecosystem, the acid-base balance will be broken, many aquatic organisms will die, nearby soil will be compacted, and production cuts in farmland crops will affect the biodiversity. It causes serious damage to the drinking water system in the living area, which worsens the disparity between supply and demand of water resources and affects human health.

Heavy metal components in heavy metal mine water are complex, because most of the nonferrous metal ore contains associated elements; so, there are cadmium, Mercury, arsenic, lead, fluorine, zinc, and other elements in the general mine wastewater. The heavy metal mine water penetrates into the groundwater through surface seepage, changing the $\mathrm{pH}$ of the water body, affecting the self-purification ability of the water body, and causing serious pollution damage to the surrounding rivers and farmland. In addition, heavy metals are difficult to degrade, and the toxicity is very strong. Plant growth has an impact and affects human health through the food chain. In China, the mine water discharged from most metal mines contains more lead and cadmium. The pollution by acidic mine water and excessive heavy metal mine water is shown in Figure 1.

Lead is one of the most common pollutants and has strong toxicity. Generally, the content of lead in water bodies will not exceed $0.01 \mathrm{mg} / \mathrm{L}$. When the concentration exceeds $0.1 \mathrm{mg} / \mathrm{L}$, it will affect the self-purification of water bodies, which will lead to algae. The death of various plants will also endanger human health through the food chain. If lead enters the human body, it will destroy the activity of protein and enzymes in the body, causing nausea and diarrhea, and lead to excessive lead ions in the blood.

Cadmium is one of the heavy metal elements that are symbiotic with zinc ore in the earth's crust and is most harmful to the human body. When cadmium ions enter the human body, cadmium can replace zinc, calcium, and other elements, which can soften the bones and affect the enzyme system in the body. In addition, the toxicity of cadmium will cause "bone pain" in Japan (long-term consumption and consumption of cadmium-containing foods). Water causes cadmium accumulation in human body and then causes kidney damage and osteoporosis.

\section{Analysis on Research Progress of Mine Water Treatment Technology}

3.1. Mine Wastewater Recycling. The resource utilization of mine wastewater is put forward on the basis of solving the two serious problems that plague the coal mine 


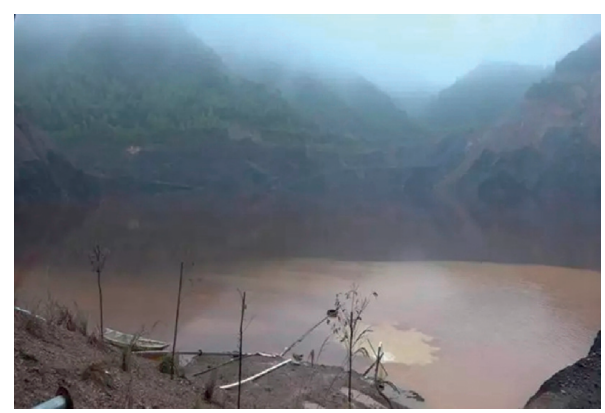

(a)

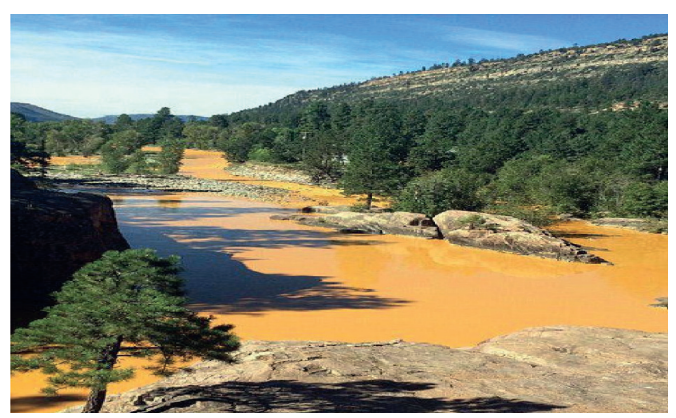

(b)

Figure 1: Schematic diagram of mine water pollution. (a) Acid mine wastewater. (b) Excessive heavy metal mine water.

industry, namely, severe water shortage in the coal mine area and environmental pollution by mine wastewater [8].

According to different mine water properties, the utilization direction of various mine waters is determined. Ensure that the mine water discharge obtained after the final treatment will not pollute the environment; reduce the discharge of COD, suspended solids, and other pollutants in the water; and reduce the impact on the nearby waters.

At present, domestic and foreign mine wastewater has the following uses: coal preparation, hydraulic transportation, water mining, and hydraulic filling; boiler, cooling, dust removal; the water extracted from the drainage borehole can be used for drinking purposes; mine wastewater can be used as a heat pump to regulate the indoor temperature of the building.

In China, the overall utilization rate of mine water is still low, with an average of only $22 \%$. China's conscious comprehensive utilization of mine water is late, and the comprehensive utilization rate is only about $15 \%$. However, with the increasing shortage of mineral water resources, many areas of the mining area have carried out various degrees of comprehensive utilization work, of which the most important is the use of industrial water, domestic water, for agricultural irrigation [9]. In addition, new utilization methods have been developed: On the one hand, use mine water and power plant waste heat to achieve office building cooling and air conditioning. Water source heat pump technology is an emerging energy-saving air-conditioning technology, which can save investment and operating costs, save energy, save water, and reduce the effect of environmental impact. On the other hand, the underground space should be treated and utilized. Mine water resources can be brought into the urban water resources management planning, and unified management can be implemented.

3.2. Mine Water Treatment Technology. For coal mine water, the most common treatment processes in China are coagulation, precipitation, filtration, adsorption, reverse osmosis, and so on. For different kinds of mine water, the treatment technology is different, and it must be treated in a targeted manner. Combined with the pollution characteristics of mine water, the treatment technology of mine water is shown in Table 1.

3.3. Dredging Water. In some large coal mines, the spatial distribution of the drain water is uneven, and in areas where the drain water is abundant, in addition to being used by itself, it will cause waste of water resources; but in an area with water shortage, no water can be used. Coal mine drainage water will lead to deterioration of water quality after the runoff mining area, which makes the water quality of mine drainage water more complicated and changeable, with high hardness and high content of iron, aluminum, and manganese. Drained water must be discharged in accordance with the requirements of the effluent water quality. After treatment, it should meet the discharge (reuse) water quality standards, that is, the concentration of suspended matter in the raw water needs to be reduced to below $50 \mathrm{mg} /$ $\mathrm{L}[10]$.

The main technological processes for the treatment of dry water are coagulation, precipitation, air floatation, filtration, and disinfection. The process uses lime milk plus soda ash to efficiently remove iron, aluminum, calcium, manganese, and other metal elements in the water, and uses the high sulfate in the raw water to remove the calcium element while removing sulfate and reducing the amount of soda ash. The drained water can be discharged into the pavement pool directly through the pipeline pump, which can be directly recycled for production and mining.

3.4. Water in the Goaf. In the process of roadway development, excavation, and construction, the water in the goaf passes through the water flowing fracture zone and carries on the roadway under the action of hydrostatic pressure, resulting in mine water disaster accidents.

For the study of water accumulation in the goaf, engineering technology is required to discharge the water accumulation in the goaf, mainly through the following methods: field survey; working face; water hole layout; 
TABLE 1: Mine water treatment technology.

\begin{tabular}{lc}
\hline Mine water type & Processing technology \\
\hline Suspended mine water & Coagulation-precipitation-filtration-disinfection \\
Acid mine water & Neutralization method, anoxic limestone ditch, permeable reaction wall, constructed wetland, \\
High-salinity mine water & sulfate-reducing bacteria reactor, continuous alkali production system \\
Heavy metal mine water & Chemical desalination, distillation, membrane separation \\
Fluoride-containing mine water & Precipitation method, adsorption method, membrane separation method \\
\hline
\end{tabular}

analysis calculation; numerical simulation; and comparative analysis method.

Technical route adopted:

(1) Collect geological and hydrological characteristics, mining conditions, and other relevant data in the study area.

(2) Perform statistical analysis on the collected data, mainly including the water layer, groundwater hydraulic connection, and stratum.

(3) Analyze the influencing factors of water accumulation in the mined-out area, and calculate the development height of the cracked zone in the mined-out area.

(4) Based on actual data, establish a hydrogeological model of the study area, and identify and verify the reliability of the model.

(5) Use the big well method and numerical simulation method to predict the water accumulation speed of the goaf.

(6) Prediction of the water accumulation space, water accumulation amount and water accumulation time of the goaf in different working faces.

3.5. Suspended Mine Water. Mine water with suspended solids contains more coal powder, rock powder, and clay in the water, which makes the mine water appear black, but the hardness and salinity are not high. Suspended matter mine water needs to choose different purification treatment methods according to the characteristics of the suspended matter.

The most basic treatment processes for this type of mine water are coagulation, precipitation, filtration, disinfection, and sterilization [11].

Coagulation is the most critical process for removing suspended solids from mine water. In the water treatment process, whether it is for the entire clarification process, pretreatment before biochemical treatment, or in-depth treatment after biochemical treatment, coagulation technology is a necessary procedure. Coagulation includes two processes: coagulation and flocculation. Coagulation refers to the action of colloidal particles and flocculants in water to neutralize and compress the electric double layer, to destabilize coagulation, and then aggregate into primary micro-flocculants. Large and dense settlement flocs are formed [12].
The removal effect of suspended matter is affected by factors such as the choice of coagulant, the dosage of coagulant, and the conditions of coagulation reaction. The effects of the three coagulants, $\mathrm{PAC}, \mathrm{FeCL}_{3}$, and $\mathrm{Al}_{2}\left(\mathrm{SO}_{4}\right)_{3}$, on mine water turbidity and SS removal rate were investigated, respectively. Turbidity and SS removal rate changes are shown in Figure 2. For the purification of suspended mine water, the most commonly used is aluminum salt or iron salt coagulant. At present, the most widely used and effective coagulant for removing suspended solids in mine water is PAC (Polyaluminum Chloride), and some will choose polyaluminum iron. The flocculant is polyacrylamide. PAC is an inorganic polymer type. It has strong adaptability to changes in $\mathrm{pH}$ and water temperature, and its turbidity removal rate is also very efficient. However, it is expensive and has certain toxicity. It is rarely used for treating mine water to convert to drinking water.

$\mathrm{Q}$. Wu has studied the mine water containing suspended solids by coagulation-microfiltration membrane separation technology, and investigated the influence of the change of microfiltration membrane operating characteristics on the membrane filtration performance and the treatment effect of this process on mine water containing suspended solids, and carried out technical and economic analysis [13].

L. Zhao has determined the optimal physical and chemical treatment process by combining the site conditions and water requirements of the Gequan mine water treatment project, that is, the "high-efficiency clarification plus gravity valveless filter" combined process, wherein traditional hydraulic cycle clarification tanks and gravity valveless filter tanks have been improved to make the operation more suitable for the purification treatment of the mine wastewater.

The problems of traditional clarifiers are pointed out: the water production capacity is small, the adaptation water quantity and the water quality change are poor, the external discharge of the sludge is difficult to control, and the surface load of the water outlet is uneven, resulting in unstable water output.

Improvement of high-efficiency clarifier: (1) In order to reduce the energy consumption of the pump, the nozzle diameter can be increased, thereby reducing the nozzle head loss. (2) The grid-reinforced reactor was added to the first reactive type of the hydraulic circulation clarifier, which strengthened the turbulent disturbance of the water flow, shortened the reaction time, and strengthened the degree of reaction. (3) Improve the radiant water collecting trough into an unequal-distance orifice water collecting trough to 


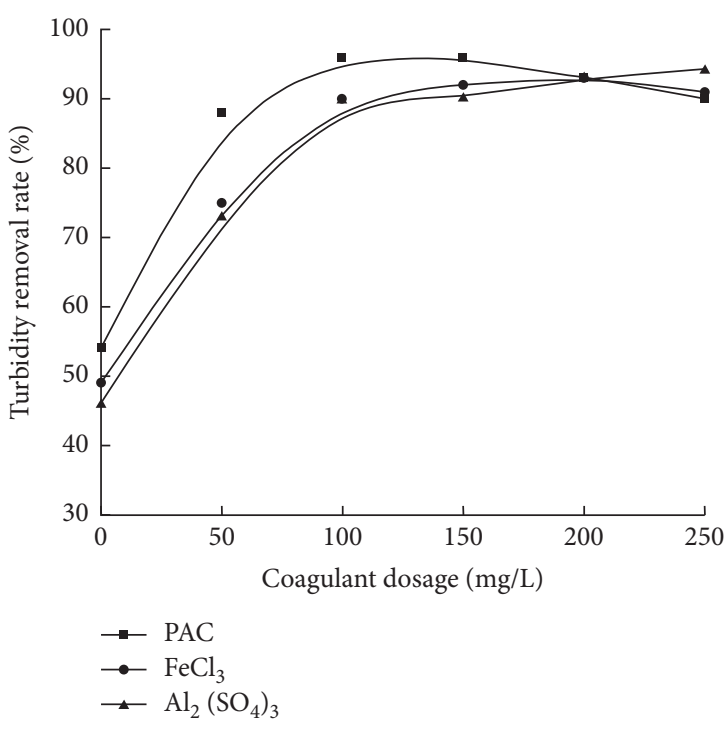

(a)

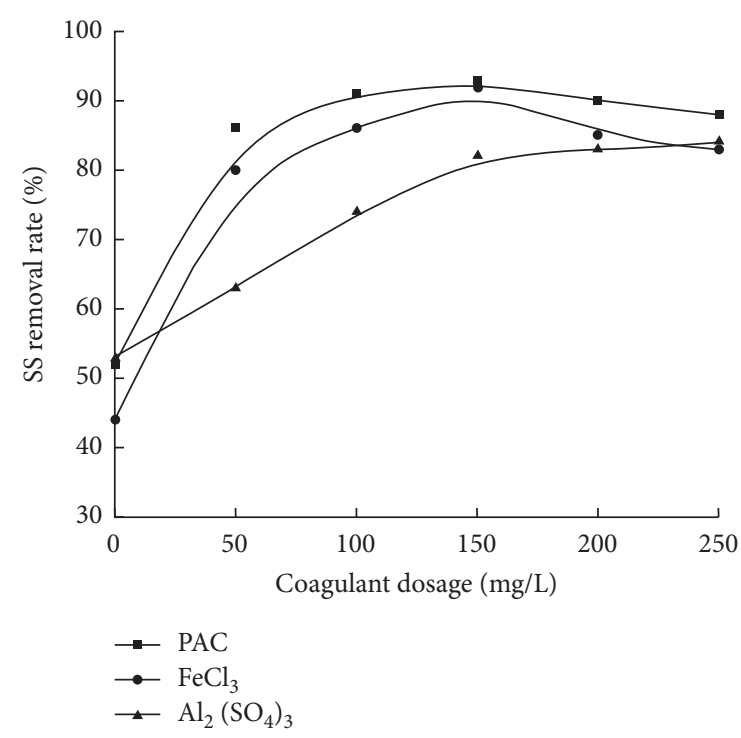

(b)

FIGURE 2: Influence of coagulant dosage on turbidity, SS removal rate. (a) Influence of coagulant dosage on turbidity removal. (b) Influence of coagulant dosage on SS.

improve the uniformity of the surface load. (4) In order to solve the problem that sludge cannot be discharged in time, which will affect the quality of the effluent, the sludge discharge system of the clarifier was renovated, and the sludge discharge time was timely, accurate, and good.

The improved clarifier is more adaptable to changes in water quantity and water quality, and the operating cost of treatment facilities is reduced to keep the effluent stable.

Problems with the traditional gravity valveless filter: the requirements for civil construction are increased; the "turning plate" in the filter plate of the water distribution system will affect the normal filtration; and the backwashing is frequent or does not automatically backwash for a longtime problem.

The improvement of the traditional gravity valveless filter: (1) The transformation of the water inlet pipe can solve the problems caused by the abnormal rise of the water level, the uniformity of the water distribution in the filter chamber is improved, and the local surface filter material collapse caused by the impact of water flow is reduced. (2) The steamwater separation device is installed on the U-shaped pipe, which can solve the problems of frequent backwashing. (3) Reform the setting method of the siphon auxiliary pipe to form a siphon backwash to reduce the loss of raw water.

The standard gravity valveless filter can basically meet all the requirements, but for different raw water quality and different purification processes, it is feasible to make some modifications to it.

3.6. High Salinity Mine Water. The pollutants of mine water with high salinity mainly include coal-based suspended solids, soluble total solids, sulfate, and chloride. The overall hardness is relatively high, and the content of pollutants exceeds the standard. The water quality of this mine water is very poor.
High-salinity mine water has three characteristics: The particle size of suspended particles is large in span, small in density, and unsuitable for settlement; the content of suspended matter is relatively unstable. The carbon molecules in the coal powder in mine water have organic reducibility, which causes the mine water to be contained. It will be removed along with the removal of suspended matter, so generally no biochemical treatment is required.

The direct discharge of mine water with high salinity will cause waste of water resources, soil salinization, and vegetation wilting, so desalination treatment is more necessary [14]. The purification treatment technology for the purpose of removing suspended solids and the advanced treatment technology for the purpose of desalination are used to realize the reuse of high-salinity mine water. The treatment process usually includes pretreatment and advanced desalination treatment.

Due to the high content of suspended matter, pulverized coal, and colloidal particles in mine water, it will gradually block the permeable membrane, reducing the permeation efficiency, and the service life of the membrane using coagulation precipitation technology.

For the desalination of mine water, the current commonly used methods for desalination include chemical methods, membrane separation methods, and distillation methods.

3.6.1. Chemical Methods. The ion exchange method is the main method of chemical desalination. Anion and cation exchangers are used to remove ions in water to reduce the salt content of water. This method is more economical for water with salt content of less than $500 \mathrm{mg} / \mathrm{L}$ and can be used as a further desalination step after high-salinity mine water is treated by membrane separation. The demonstration of ion exchange principle is shown in Figure 3. 


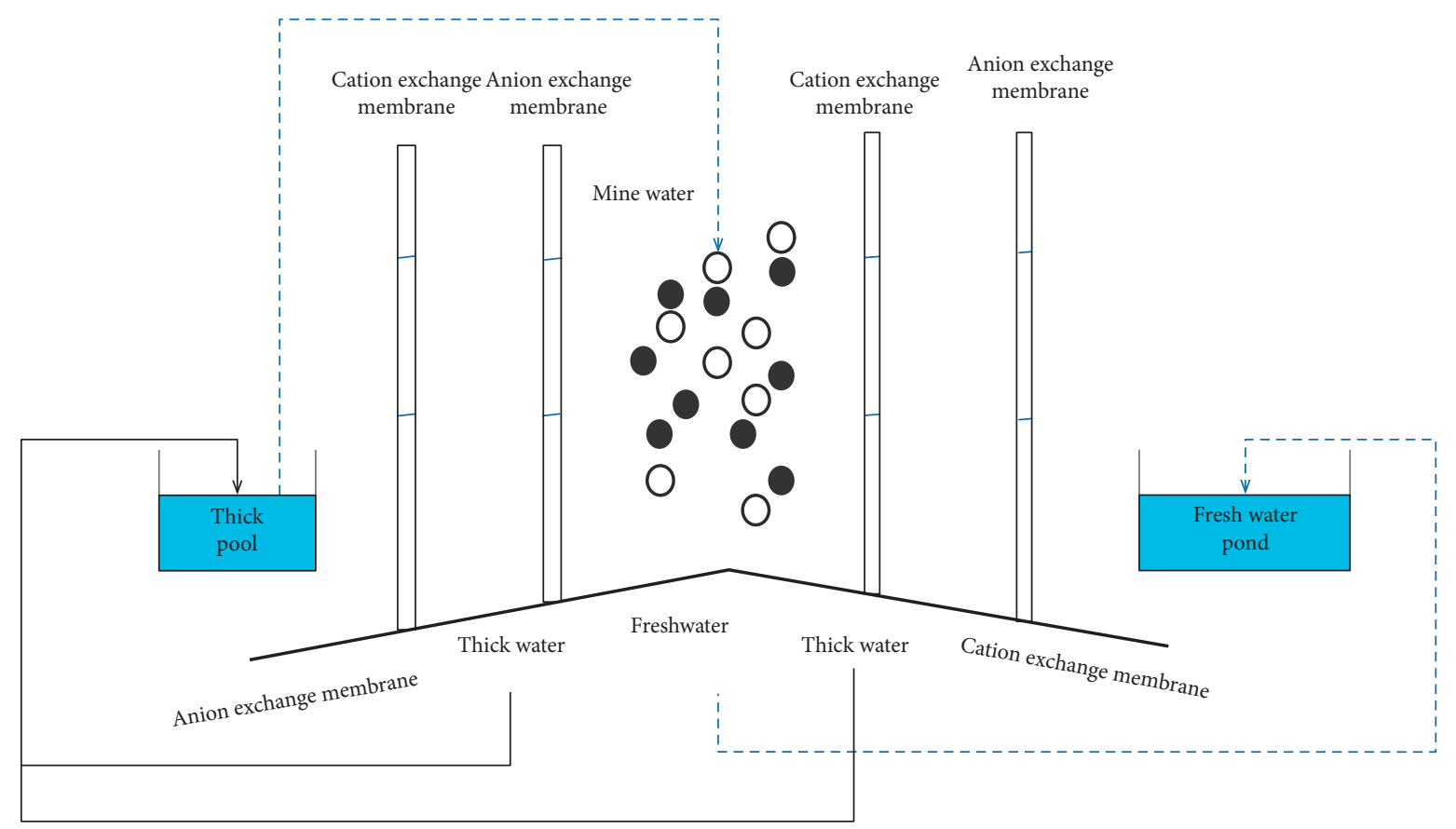

Figure 3: Schematic diagram of ion exchange.

3.6.2. Membrane Separation Method. Membrane separation method uses selective permeable membrane as the separation medium. When there is a certain driving force (such as pressure difference, concentration difference, potential difference) on both sides of the membrane, the solvent will be separated from the solute or particles. The most common techniques of membrane separation are reverse osmosis and electrodialysis.

The membrane separation method has the advantages of high efficiency, low energy consumption, simple device, wide application, and easy operation. Membrane water treatment has the characteristics of strong adaptability, small footprint, high efficiency, and simple and economical operation. However, the biggest disadvantage of membrane separation is membrane fouling. In order to prevent membrane fouling, the inlet water quality of these two technologies must meet strict requirements, so the inlet water must be pretreated. The general pretreatment process is coagulation, precipitation, filtration, adsorption, and disinfection.

\section{(1) Reverse osmosis}

Reverse osmosis RO technology was applied in foreign aerospace technology research in the 1950s and 1960s, and it was actually applied in China in the early 1980s. Reverse osmosis technology is a membrane separation technology powered by pressure difference. It can remove various impurities including ions, molecules, organic matter, colloids, bacteria, viruses, and other water. This new technology is suitable for water treatment with salt content more than $4000 \mathrm{mg} / \mathrm{L}$.

The basic process flow of reverse osmosis treatment is shown in Figure 4.
C. R. Wang has studied mine water in the Xuzhuang Coal Mine after pretreatment of de-suspension, and then through multimedia filtration and activated carbon filtration pretreatment process and reverse osmosis desalination treatment process to achieve high-salinity mine water reuse [15].

C. Tang has used magnetic separation and D-type filter technology to remove suspended solids, ultrafiltration equipment was used to further remove colloids and suspended solids, and reverse osmosis and nanofiltration equipment were used for desalination to achieve the mine water treatment effect [16].

\section{(2) Electrodialysis}

The process flow diagram of electrodialysis device is shown in Figure 5. The electrodialysis method ED refers to a method for separating water and impurities using electrical energy. There are two basic conditions for salt removal by electrodialysis: one is the chargeability of ions; the other is that the ion exchange membrane has selective permeability.

The electrodialysis desalination method does not require the addition of any chemical agents, the equipment is simple, and the assembly and operation are convenient. However, this technology also has some disadvantages in certain aspects, such as: high-water quality requirements; high power consumption, membrane surface is prone to fouling, and membrane life is short; the electrodialysis module is made of plastic material, which is easy to be aged, resulting in the increase of maintenance cost; the water quality and quantity of water in the electrodialysis process can affect the current and voltage during the operation. The 


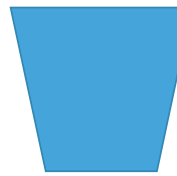

High salinity mine water
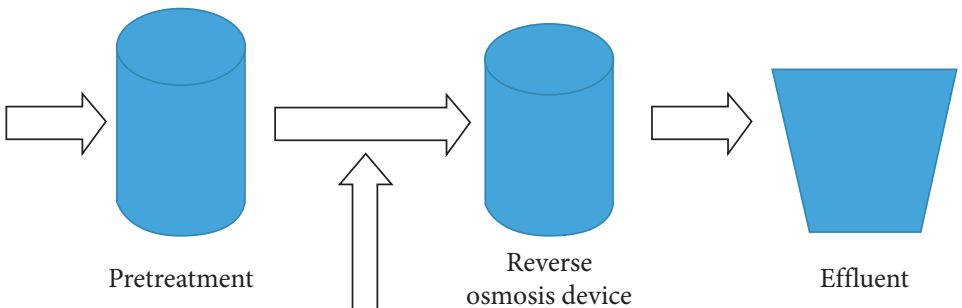

osmosis device

Effluent

\section{Add antiscalant}

FIgURE 4: Reverse osmosis process.

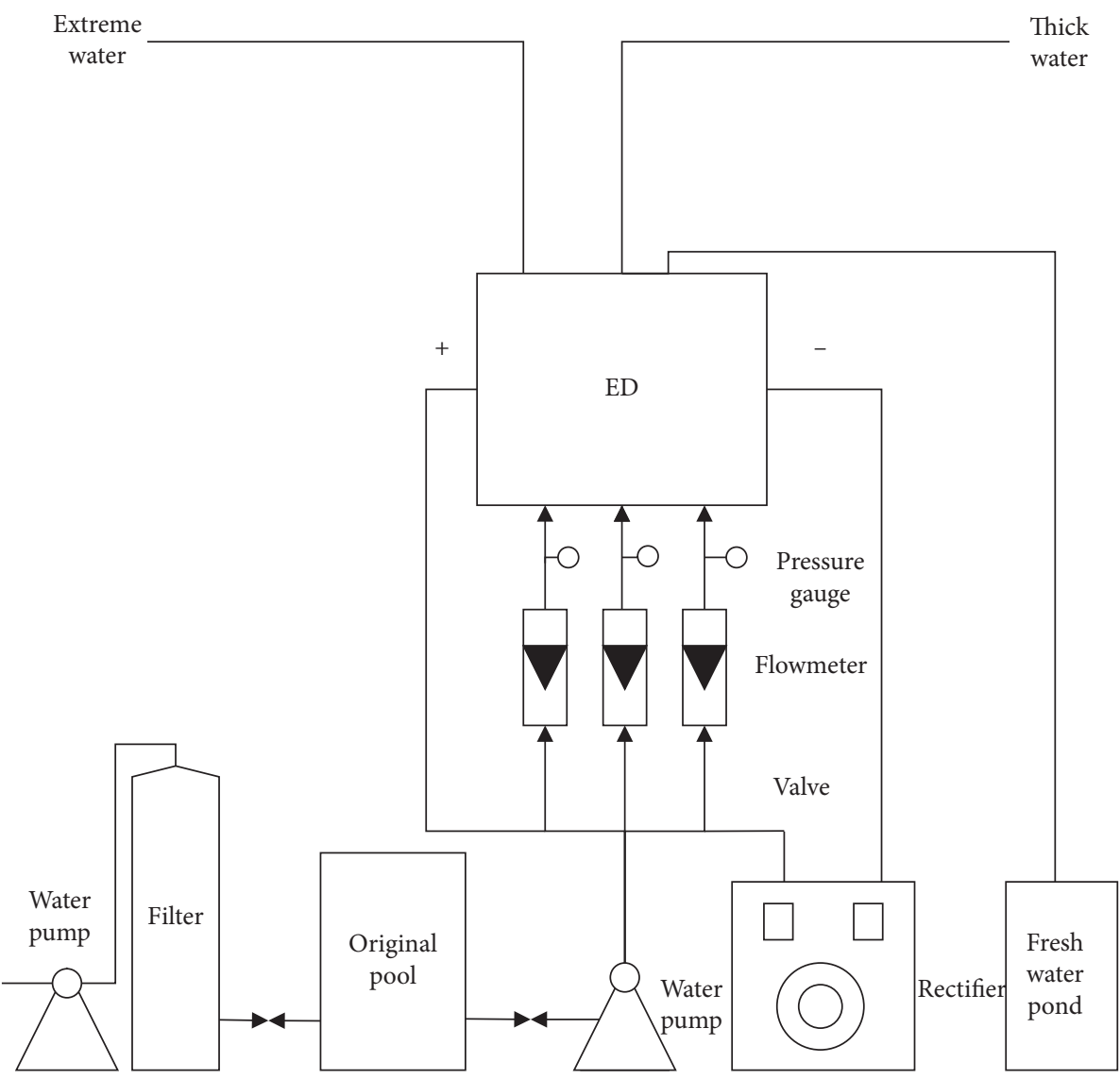

FIgURE 5: Process flow diagram of electrodialysis device.

desalination process is unstable and is prone to performance degradation.

Cui et al. jointly treated mine water through the coagulation-electrodialysis method, so that the treated mine water met the drinking water quality requirements. The best coagulant, the best voltage, and time of ion removal are determined, and the energy consumption is minimized [17].

\section{(3) Distillation}

Distillation is an effective method of using thermal treatment of brine to achieve desalination [18]. The heat energy consumed by this method is very large, which is suitable for the treatment of mine water with a salt content exceeding $3000 \mathrm{mg} / \mathrm{L}$.

Due to the high energy consumption of the distillation method, the popularization and application of this 
method has also been hindered. But, it has its own unique advantages: it does not require any chemicals or ion separation membranes; the range of salt content in the treatment of mine water is very wide; the water quality of the incoming water is not high; this method produces distilled water and the rate of desalination is relatively high.

\subsection{Acid Mine Water}

3.7.1. Formation of Acid Mine Water. To analyze and process the acid mine water, we first need to understand the formation of coal mine acid water: in coal operations; the mining process will destroy the original reduction environment of the coal seam, and the pyrite in the coal seam and its surrounding rocks is oxidized to reduce under the action of oxygen. In the form of sulfides, groundwater is in contact with the top and bottom of the coal seam, which oxidizes the sulfides into sulfuric acid, which makes the water acidic. However, the formation of acid mine water is a complicated process, which is related to many factors, such as chemistry, physics and biology. The main reactions are as follows:

(1) First, pyrite ore reacts with mine water to generate sulfuric acid and ferrous sulfate.

$$
2 \mathrm{FeS}_{2}+7 \mathrm{O}_{2}+2 \mathrm{H}_{2} \mathrm{O}=2 \mathrm{FeSO}_{4}+2 \mathrm{H}_{2} \mathrm{SO}_{4} \text {. }
$$

(2) The ferrous sulfate continues to react to form ferric sulfate and other metal sulfates.

$$
\begin{aligned}
4 \mathrm{FeS}_{2}+15 \mathrm{O}_{2}+2 \mathrm{H}_{2} \mathrm{O} & =2 \mathrm{Fe}_{2}\left(\mathrm{SO}_{4}\right)_{3}+2 \mathrm{H}_{2} \mathrm{SO}_{4}, \\
4 \mathrm{FeSO}_{4}+2 \mathrm{H}_{2} \mathrm{SO}_{4}+\mathrm{O}_{2} & =2 \mathrm{Fe}_{2}\left(\mathrm{SO}_{4}\right)_{3}+2 \mathrm{H}_{2} \mathrm{O}
\end{aligned}
$$

The produced high-iron sulfate has the function of dissolving various sulfide minerals.

$$
\begin{aligned}
2 \mathrm{Fe}_{2}\left(\mathrm{SO}_{2}\right)_{3} & +2 \mathrm{MS}+2 \mathrm{H}_{2} \mathrm{O}+3 \mathrm{O}_{2} \\
& =2 \mathrm{MSO}_{4}+4 \mathrm{FeSO}_{4}+2 \mathrm{H}_{2} \mathrm{SO}_{4} .
\end{aligned}
$$

(3) Hydrolysis reaction. The high-speed sulfate produced in the second step will undergo a hydrolysis reaction when the $\mathrm{pH}$ value of the aqueous solution is greater than 3.5 .

$$
\mathrm{Fe}_{2}\left(\mathrm{SO}_{4}\right)_{3}+6 \mathrm{H}_{2} \mathrm{O}=2 \mathrm{Fe}(\mathrm{OH})_{3}+3 \mathrm{H}_{2} \mathrm{SO}_{4} \text {. }
$$

(4) The role of microorganisms in the formation of acidic water in sulfide ores: Some research data indicate that microorganisms play a very important role in the oxidation process of sulfide ore deposits. Thiobacillus ferro oxidants can transform iron, zinc, copper, arsenic, and nickel Such sulfide minerals are oxidized to produce sulfuric acid and sulfate. For the typical mineral $\mathrm{FeS}_{2}$ that produces acidic water, microorganisms play an extreme role in its oxidation process, making its natural oxidation rate slower [19].
3.7.2. Source and End Treatment of Acid Mine Water. For acid mine water, the treatment is mainly meant to control the water source, but in practical applications, the treatment effect is more affected by the outside world.

In the application of the mine environment, there are many difficulties in the control of the source, so the end treatment of acid mine water has been studied more extensively [20]. AMD source and end-processing technology is shown in Figures 6 and 7.

(1) Neutralization method: the neutralization method is the most widely used treatment technology for acid mine water. Neutralizing agents are added to acidic wastewater to increase the $\mathrm{pH}$ of the wastewater. Under alkaline conditions, metal ions generate hydroxide precipitates and are removed from the wastewater. Commonly used neutralizing agents are lime, limestone, sodium carbonate, sodium hydroxide, etc.

Ding and Ding have used the limestone-lime milk, twostage neutralization method to treat mine acid wastewater. In Suichang Gold Mine, the amount of sediment produced by this method is only one third of that produced by lime milk neutralization method, which reduces the overall processing cost [21].

(2) Anoxic limestone ditch: anoxic limestone ditch is a process in which acid mine water flows through the limestone gully to dissolve limestone continuously, thereby generating alkalinity. Therefore, the method is particularly economical and has been widely used abroad [22]. ALDs are very effective for the neutralization of acidic water; when using this method, combined with other passive methods, it can greatly improve the efficiency of wastewater treatment and reduce the area of the treatment facility.

Genty et al. have used batch reaction and reaction column methods to study ALDs. The results show that the smaller the particle size, the higher the alkali production capacity, but ALDs are not suitable for the treatment of high-concentration acid mine wastewater [23].

(3) Permeable reaction wall: the principle of permeable reaction wall combined with microbial remediation is used for acid mine water treatment [24]. The permeable reaction wall is obtained by digging a ditch in the direction of mine water flow and filling the ditch with active materials (such as organic solid mixture, limestone, or gravel). In the reaction wall, reducing microorganisms produce alkalinity after growing, and at the same time, the alkalinity generated by the dissolution acts on the wastewater together, removing metal ions as hydroxides, sulfates.

(4) Constructed wetland: the wetland system is very distinctive and unique. It contains the soil and substrate of the wetland, unique hydrological conditions, and wetland organisms [25]. Among them, the soil-plants first intercept the suspended matter in the acid mine water by adsorption and filtration. The metal ions 


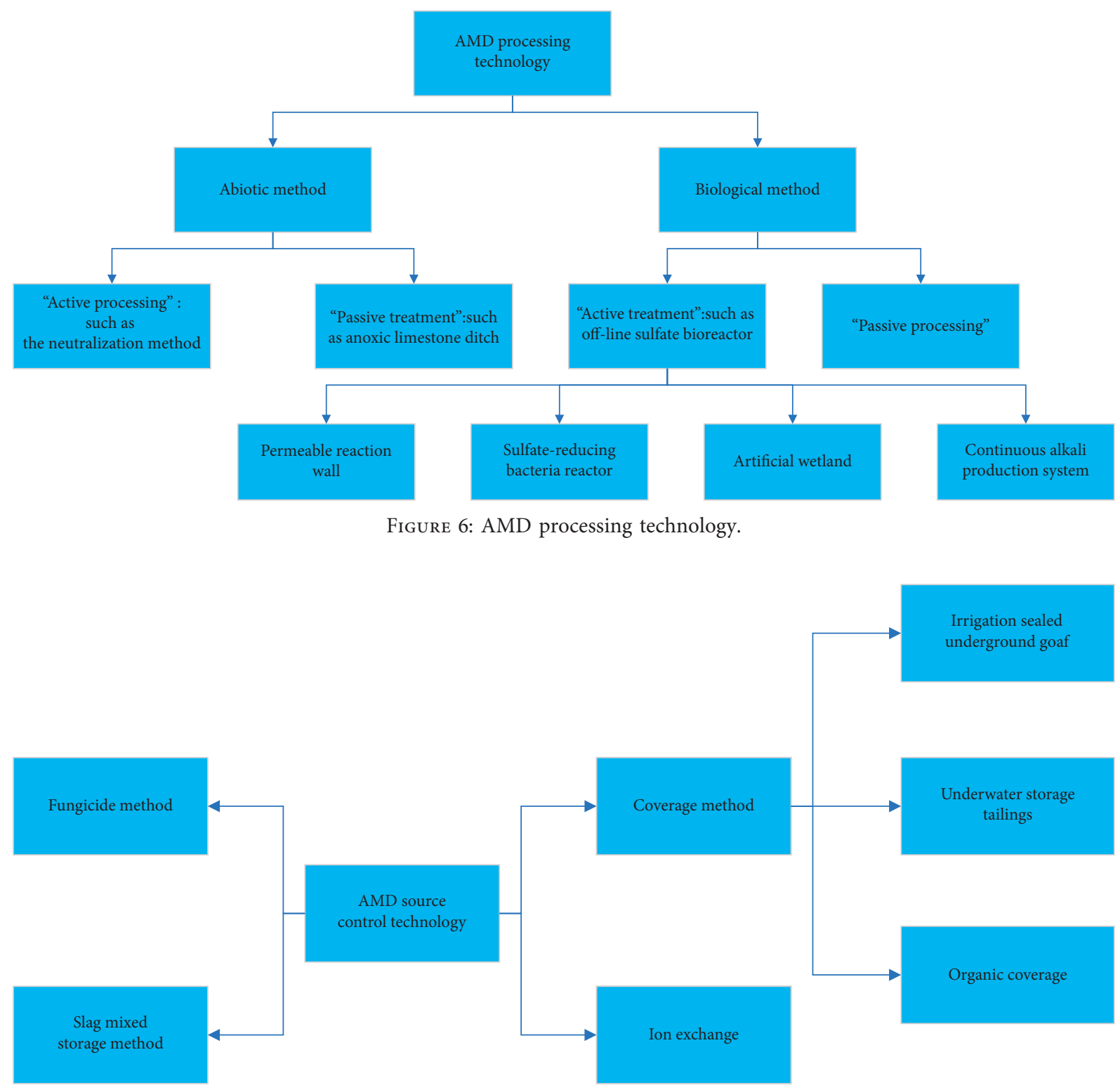

FIGURE 7: AMD source control technology.

deposited in the wetland system are removed from the water by ion exchange, oxidation, hydrolysis, and microbial action.

Constructed wetland is a new type of ecological sewage treatment technology, which has the characteristics of low investment, low energy consumption, simple operation and maintenance, and high treatment efficiency [26].

(5) Sulfate-reducing bacteria reactor (SRB): SRB is an emerging acid mine water biological treatment technology. In this technology, in a sufficient environment, organic matter acts as an electron donor for $\mathrm{SRB}$, and as an electron acceptor, oxidizes the organic matter, and obtains the energy required for life through the alienation of the organic matter, while reducing it.
Sanchez has used domestic sewage as an SRB carbon source to mix with acid mine water for treatment [27]. Liu has made a pilot-scale UASB sulfate-reducing bacteria bioreactor at the Zijinshan Copper Mine to treat mine wastewater. The project includes a two-stage sedimentation tank and a UASB reactor. The carbon source comes from activated sludge after sewage treatment [28].

(6) Continuous alkali production system: the continuous alkali production system can continuously produce alkalinity during the flow of acid mine water. Because the process is in an anaerobic environment, it will not produce hydroxide precipitation on the limestone surface and affect the alkali production process. It combines the characteristics of anaerobic constructed wetland method, sulfate-reducing bacteria 
method, and anoxic limestone ditch method, and also solves the defects of these methods when used alone.

Chen and others have used calcined carbonate rock in the continuous alkali production system, which failed to demonstrate the superiority of the shake flask experiment. The acid mine water treatment capacity was only slightly higher than that of the original rock. The complete set of treatment technology based on the continuous alkali production system can remove the sulfate and metal ions in acid mine water, step by step. It has a stable and lasting treatment effect. It is suitable for changing water quality conditions and can be constructed in the field.

3.8. Specially Contaminated Mine Water. Mine water with special pollutants refers to mine water with fluoride and heavy metal toxic substances. Such mine water is more polluted and difficult to handle. Arbitrary discharge will destroy the ecological environment and affect the utilization of mine water resources.

3.8.1. Fluoride-Containing Mine Water. China's Hebei, Henan, Shaanxi, Gansu, Qinghai, Xinjiang, and other places are high-fluorine areas. If the fluorine-containing water in the mining area is discharged without treatment, human and livestock drinking this high-fluorine water for a long time will cause chronic poisoning. Osteoporosis in mild cases, convulsions and cramps in severe cases, and even death from respiratory paralysis can also cause various skin diseases.

When groundwater flows through a mine rich in fluorine, after years of physical and chemical action, the solid state of the fluorine mountain migrates into the mine water, resulting in high fluoride in the coal mine water [29].

Because fluoride is a toxicological index, the water quality of the effluent is relatively strict. Commonly used defluorination processes include electrodialysis, ion exchange, chemical precipitation, etc.

(1) Electrodialysis method: this method relies on F- in aqueous solution under the action of an external electric field, through an ion-exchange membrane with selective permeability, so that F- that migrates together with mineral ions in aqueous solution to concentrated water was removed. The main advantage of this method is its simple operation. The disadvantages are as follows: (1) while removing F-, the minerals that are beneficial to the human body in the water are removed, making the treated water often not suitable for direct drinking; (2) when the fluorine content is higher than $3 \mathrm{mg} / \mathrm{L}$, it is difficult to remove F- at one time to meet drinking water standards; (3) equipment investment is large, not suitable for largescale water treatment projects; (4) water yield is low, generally only $50 \%$, and water resources are wasted; (5) equipment management is complicated and cost is high. In view of the above reasons, the F- method of electrodialysis is rarely used in actual water treatment projects.
(2) Ion exchange method: this method relies on the ionexchanger and F-adsorption exchange function in water to facilitate the removal of insoluble fluorides. This method, especially represented by activated alumina, is currently widely used in small domestic F-removal devices. The main advantage of this method is that the treated water meets the standard once, without changing the mineral composition of the water. The problems are as follows: (1) large onetime investment and high water treatment cost; (2) inorganic ion exchanger declines rapidly, and the exchange capacity is significantly reduced; (3) inorganic ion exchanger needs to be regenerated repeatedly, and the operation is troublesome.

(3) Chemical precipitation method: It is to add a certain amount of cation and F- into the aqueous solution to form an insoluble electrolyte, which produces a precipitate and is separated from water to remove F-. This method is mainly used in the treatment of some industrial wastewater with high content of $\mathrm{F}$ $(20-4000 \mathrm{mg} / \mathrm{l})$. Because the solubility of $\mathrm{CaF}_{2}$ is $16 \mathrm{mg} / \mathrm{L}$, even if an excessive amount of $\mathrm{Ca}^{2+}$ is added, the residual amount of $\mathrm{F}$ - in its aqueous solution is difficult to be lower than $8 \mathrm{mg} / \mathrm{L}$, so this method is not suitable for drinking water treatment with low F-.

3.8.2. Heavy Metal Pollution Mine Water. At present, the development and mining activities of mineral resources containing heavy metals have increased sharply, which has led to the production of large amounts of heavy metal wastewater in nonferrous metal mine mining and beneficiation operations, causing serious environmental pollution problems. Most nonferrous metal mines contain sulfur or symbiotic sulfides, such as pyrite, chalcopyrite, and other minerals. The sulfide in nature undergoes the comprehensive reaction of oxidation, weathering, decomposition, and water-gas-acid-mineral reaction, and can form acidic wastewater unique to mines. Most metal sulfide beds contain iron sulfide ore. The process of formation of acidic wastewater in mines is the oxidation of iron sulfide. The formation of acidic wastewater containing multiple metal ions is caused by the further reaction of sulfuric acid, ferric sulfate, etc., formed by the oxidation of iron sulfide with ores containing various metal ions.

Under the action of water and air, sulfide minerals react to form sulfuric acid, which eventually generates mine acidic heavy metal wastewater containing iron and other metal ions [30]. Because most nonferrous metals and ores contain associated elements, and the heavy metal components contained in the wastewater of nonferrous metal mines are relatively complex, elements such as mercury, arsenic, lead, cadmium, copper, zinc, and chromium are often present in general wastewater. Heavy metal ions are difficult to be degraded by microorganisms and are persistent toxic pollutants. Under the action of microorganisms, some heavy metals can even be converted into more toxic substances, such as metal-organic compounds, which not only affects the growth and production of animals and plants but also enters 
the human body through bioaccumulation and biomagnification of the food chain in the living body and may eventually damage human health.

Current status of heavy metal wastewater treatment: at present, there are a variety of treatment technologies for heavy metal wastewater, but there are three main types of methods for the treatment of heavy metal ion-containing wastewater. Heavy metal ions are precipitated and removed, mainly including neutralization precipitation method, sulfide precipitation method, ferrite precipitation method, etc.; the second type is the physical chemical method, that is, without changing the chemical conditions of heavy metal ions, by using physical separation to remove heavy metal ions in wastewater, there are mainly ion exchange method, adsorption method, and membrane separation method; the third type is to use the biological method to remove heavy metal ions in wastewater, the biological method is to use microorganisms and certain aquatic plants to absorb heavy metal ions in water. The heavy metal ions are adsorbed and fixed, and gradually accumulated to increase the amount of adsorption to remove heavy metals from wastewater. The main methods include the biological adsorption method and constructed wetland method.

The above method has a good treatment effect for heavy metal ion wastewater with conventional content, but it does not mean that all are suitable for treating low-concentration heavy metal ion wastewater. Regarding the water quality characteristics of nonferrous metal mining well water with low BOD, low $\mathrm{pH}$, and the coexistence of lead, cadmium, and arsenic, the content of heavy metals required for advanced treatment in heavy metal wastewater is relatively low. Therefore, it is very important to study effective methods for treating low-concentration heavy metal wastewater.

H. Zhao and F.Q. Li have used the chitosan complexultrafiltration coupling process to treat heavy-metal-simulated wastewater in nonferrous metal mines. The main removal materials were lead ions and cadmium ions. The $\mathrm{pH}$ value, mass ratio, ionic strength, and other factors were investigated for the retention of heavy metal ions The effect of the rate and membrane flux verified the effect of recovering chitosan after acidification-decomplexation [30].

Z. Huang and J.P. Xu have domesticated the tolerance of SRB heavy metals, and optimized the process conditions of $\mathrm{SRB}$ system, Fe-C system, and SRB/Fe-C system for processing heavy metal ions, combined with permeable reaction bed (PRB) Structural design; the effect and influencing factors of in-situ treatment of heavy metal ions in acid mine water were studied [31].

J.X. Chen has introduced the separation mechanism and simple process technology of ion exchange resin and its research and application in the treatment of heavy metal wastewater, and introduced the research and development and research results of the use of ion exchange resin to treat heavy metal wastewater in recent years [32].

\subsection{New Technology}

3.9.1. The Medium Membrane Ultrafiltration Membrane Product Was Successfully Applied to the National Energy Group's Large-Scale Mine Dewatering and Reuse Project. In this project, in the face of the water treated by the coagulation plus heavy medium speed sink and V filter process, Beijing Zhonghuan Membrane Material Technology Co., Ltd. (referred to as: Central Ring Film) of the Botian Environmental Group uses thermal ultrafiltration membrane products, using the ultrafiltration plus reverse osmosis process to build a mine water reuse project with a scale of 30,000 tons per day in two phases, while achieving environmental protection standards, reducing the water consumption rate of industrial output value of enterprises, and creating an economy for enterprises benefit. The application system of mid-ring membrane thermal ultrafiltration membrane is shown in Figure 8.

According to reports, Botian Environment and user units have fully demonstrated in the early stage of the project, and have made careful considerations and project management from design, process, and parameter selection, equipment matching, installation implementation, and commissioning operation, and finally realized the ultrafiltration membrane. The operation of the device and the whole system is stable, ensuring that the overall water reuse rate index and the outflow index of the system meet the requirements, realizing the dewatering and reuse of the mine.

The project is expected to reduce nearly 8.5 million tons of annual emissions, and the treated water can be effectively used in industrial production and other purposes in general. The project will reduce the environmental cost of customers and promote the sustainable use of water resources.

Membrane products have been successfully applied in hundreds of cases in more than 20 industries around the world. With innovative technology and adherence to the quality of the ingenuity, the Central Membrane is bound to turn the project into another benchmark project in the field of deep reuse of mine water.

\subsubsection{Harbin $0.5-50 \mathrm{~m}^{3} / \mathrm{h}$ Production Wastewater Treatment} Project. Biochemical Oxygen Demand (BOD) is the amount of dissolved oxygen consumed by the biochemical processes performed by microorganisms in decomposing certain oxidizable substances in water, especially organic substances, under specified conditions. The larger the BOD value, the more pollutants in the water, and the more serious the pollution. BOD is an environmental monitoring method, suitable for monitoring water pollution.

The adjustment tank of Harbin $0.5-50 \mathrm{~m}^{3} / \mathrm{h}$ sewage treatment adopts the aeration method to balance water quality and water volume, avoiding the precipitation caused 


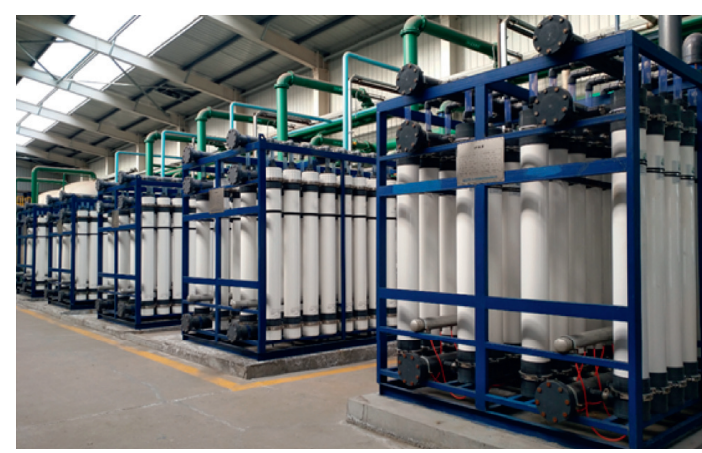

Figure 8: Mid-ring membrane thermal ultrafiltration membrane.

by aeration and stirring. An anaerobic tank is installed after the adjustment tank, and the aerobic treatment adopts a twostage biological contact oxidation process. Sewage treatment process is an urban sewage treatment process developed on the basis of traditional technology.

The structure includes a tank, filler, water distribution device, and aeration device. The working principle is that the filler is installed in the aeration tank and used as the carrier of the biofilm. After aeration, the wastewater to be treated flows through the filler at a certain flow rate. After the completion of the packing, contact with the biofilm and work together. Anaerobic biological treatment is a method of using facultative anaerobes and specific anaerobes to degrade macromolecular inorganic substances into lowmolecular compounds, and then convert them into methane and carbon dioxide, to treat inorganic wastewater. It can be divided into acid digestion. Two stages and alkaline digestion: In the acid digestion stage, exogenous enzymes secreted by acid-producing bacteria convert macromolecular inorganic substances into complex inorganic acids and alcohols, aldehydes, ammonia, carbon dioxide, etc. In the alkaline digestion stage, the metabolites of acid digestion are further broken down into methane, carbon dioxide, and other biological gases.

The advantages of this method are as follows: (1) It can reduce the floor space, the parking lot can be built above the equipment, and there is no need to build facilities. (2) There is no impact on the surrounding environment, the amount of sludge generated is small, and the noise is less than the standard of the second category. (3) It is easy to operate, new technology, good effect, and long service life. (4) Equipment can be arranged according to the standard, or it can be specially arranged according to the terrain.

3.9.3. Water Retention Coal Mining. Water retaining coal mining is a kind of coal mining technology which can keep aquifer structure stable or water level change in a reasonable range by controlling rock movement in arid or semi-arid areas. It is a new coal mining technology to seek the optimal solution between coal mining capacity and water resources carrying capacity.

The premise of coal mining and water conservation is that there is water and coal, and they needs to be protected. If there is coal, it is possible to collect it. Water conservation under coal mining conditions is to protect the environment and protect the ecology.

In the northern part of Shanxi, there are two ways to achieve coal mining and water conservation. One is to rationally select the mining area (mainly in the planning stage of the mining area) and the second is to adopt reasonable coal-mining methods and engineering measures (such as filling mining).

\section{Conclusion and Outlook}

China is a large mineral resource country. The exploitation and utilization of mineral resources is very important, and the treatment of mine water is vital to the overall environment. In general, the most widespread mineral water pollution is acid mine water, and the most serious pollution is heavy metal mine water. For different mine waters, it is necessary to adopt a relatively appropriate method. Each treatment technology has its advantages, characteristics, and deficiencies. It is necessary to select the correct process according to the specific conditions to ensure reasonable technology and economical energy conservation.

There are new technologies, such as "high-efficiency clarification plus gravity-type valveless filter," for mine water containing suspended solids. For high-salinity mine water, reverse osmosis has been applied more highly. For acid mine water, the most widely used method is the limestone trench method, and there are also many emerging treatment technologies, such as sulfate reduction bacteria reactor. The treatment method of fluoride-containing mine water widely used in China is the ion exchange method, and for heavy metal mine water, the precipitation method is widely used due to its mature technology. The treated mine water can reduce the malignant impact of the direct discharge of mine water on the whole environment, and can also reuse the wastewater to improve the water shortage in the mining area after production.

The impact of mine water on the environment has become a hot issue globally. The formation, prediction, and control of mine water pollution types and the development of new technologies are not only the challenges faced by environmental disciplines in various countries but also the important problems that must be solved for the sustainable development of national economy and society.

\section{Data Availability}

The data used to support the findings of this study are included within the article.

\section{Conflicts of Interest}

The authors declare that they have no conflicts of interest regarding the publication of this paper.

\section{Acknowledgments}

This study was financially supported by the National Natural Science Foundation of China (Grant No. 51904266), the National Social Science Foundation emergency management 
project (Grant No. 20VYJ021), and Key Laboratory of Safety and High-Efficiency Coal Mining, Ministry of Education (Anhui University of Science and Technology (Grant No. JYBSYS2018203).

\section{References}

[1] F. Liu, W. J. Cao, J. J. Zhang et al., "Current technological innovation and development direction of the 14 th Five Year Plan period in China coal industry," Journal of China Coal Society, vol. 46, no. 1, pp. 1-15, 2021.

[2] J. F. Lou, H. P. Kang, F. Q. Gao et al., "Determination of largeheight support resistance based on multi-factor analysis," Journal of China Coal Society, vol. 42, no. 11, pp. 2808-2816, 2017.

[3] J. F. Lou, F. Q. Gao, J. H. Yang et al., "Characteristics of evolution of mining-induced stress field in the longwall panel: insights from physical modeling," in International Journal of Coal Science \& Technology, Springer, Berlin, Germany, 2021.

[4] W. Suo, Discussion on the Status Quo and Treatment Technology of Mine Water, China Agricultural University, Beijing, China, 2015.

[5] Y. B. Zhang, "Application of magnetic separation water treatment technology in western waterrich mines," Journal of Mining and Safety Engineering, vol. 30, no. 2, pp. 371-373, 2013.

[6] Z. Yuan, Research on Water Resources Environmental Safety Assessment System in Northern Shaanxi Mining Area, Xi'an University of Science and Technology, Xi'an, China, 2010.

[7] Z. Miao, "Hydrogeological characteristics and water damage prevention in coal mine goaf," Chinese Science and Technology Periodical Database Engineering Technology, vol. 12, no. 4, p. 231, 2017.

[8] J. Liu, Study on Environmental Impact and Coal Mine Wastewater Resource Utilization in Coal Mining in Western District of Linshui County, Chengdu University of Technology, Chengdu, China, 2007.

[9] W. F. Wan, Research on Mine Water Resources in Binchang Mining Area and Optimized Site Selection of Water Purification Plant in Hangkou Power Station, Chang'an University, Xi'an, China, 2006.

[10] W. Jia and D. Y. Li, "Study on the treatment technology of dewatering water in open pit coal mine," Opencast Mining Technology, vol. 42, no. 3, pp. 42-46, 2012.

[11] L. Zhao, Application of "High Efficiency Clarification + Gravity Valveless Filter" in Mine Wastewater Treatment, Tianjin University, Tianjin, China, 2012.

[12] Y. L. Jia, Research on Key Technology Application of High Suspended Matter and High Salinity Mine Water Resources, Hebei University of Engineering, Handan, China, 2015.

[13] Q. Wu, Z. Q. Wang, S. Y. Ye et al., "Experimental study on coagulation-microfiltration membrane separation technology in mine water treatment and reuse," Journal of China Coal Society, vol. 29, no. 5, pp. 581-584, 2004.

[14] D. W. Zhai and G. R. Ge, "New technology for energy saving desalination of high salinity mine water," Coal Science and Technology, vol. 46, no. 9, pp. 12-18, 2018.

[15] C. R. Wang, "High-mineralization mine water treatment technology and engineering practice in Xuzhuang Coal Mine," Energy Environmental Protection, vol. 36, no. 2, pp. 36-37, 2014.

[16] C. Tang and J. Wang, "Engineering practice of high salinity mine water treatment and utilization," Inner Mongolia Coal Economy, vol. 5, pp. 58-59, 2019.
[17] L. Cui and R. F. Qiu, "Study on the treatment of high salinity mine water by coagulation-electrodialysis," Journal of Shanxi University, vol. 33, no. 4, pp. 591-595, 2010.

[18] H. Xu and Y. Wang, "Formation and main treatment technology of acid mine water in coal mines," Environmental Science and Management, vol. 33, no. 9, pp. 100-102, 2008.

[19] L. B. Liu, Study on Pollution Characteristics and Chemical Control Methods of Acid Drainage in Guizhou Coal Mining Area, Guizhou University, Guiyang, China, 2009.

[20] Y. Chen, Method Construction and Stability Study of Acid Alkali Wastewater Treatment by Continuous Alkali Production System, Guizhou University, Guiyang, China, 2015.

[21] C. S. Ding, "Treatment of mine acid wastewater by limestonelime milk second-stage neutralization method," Energy Environmental Protection, vol. 18, no. 2, pp. 27-29, 2004.

[22] R. R. Zhang, "Treatment of acid mine water by anoxic limestone ditch method," Coal Mine Environmental Protection, vol. 12, no. 1, pp. 38-39, 1998.

[23] T. Genty, B. Bussière, R. Potvin, M. Benzaazoua, and G. J. Zagury, "Dissolution of calcitic marble and dolomitic rock in high iron concentrated acid mine drainage: application to anoxic limestone drains," Environmental Earth Sciences, vol. 66, no. 8, pp. 2387-2401, 2012.

[24] J. P. Xu and H. J. Wan, "Study on treatment of acid mine wastewater by using activated carbon," Water Treatment Technology, vol. 40, no. 3, pp. 57-63, 2014.

[25] L. Dou, "Study on treatment mechanism of heavy metal constructed wetland in acid mine water," Environmental Science and Technology, vol. 29, no. 11, pp. 109-111, 2006.

[26] A. G. Qin, "Study on the effect of outlet location on the denitrification effect of combined subsurface flow constructed wetland," Guangxi Light Industry, vol. 12, no. 133, pp. 90-92, 2009.

[27] I. Sánchez-Andrea, D. Triana, and J. L. Sanz, "Bioremediation of acid mine drainage coupled with domestic wastewater treatment," Water Science and Technology, vol. 66, no. 11, pp. 2425-2431, 2012.

[28] X. Y. Liu, G. Zou, X. Q. Wang et al., "A novel low pH sulfidogenic bioreactor using activated sludge as carbon source to treat acid mine drainage (AMD) and recovery metal sulfides: pilot scale study," Minerals Engineering, vol. 48, pp. 51-55, 2013.

[29] Q. S. Zhu and G. Q. Xu, "Current status and research progress of fluorine pollution in groundwater in China," Environmental Science and Management, vol. 34, no. 1, pp. 42-44, 2009.

[30] H. Zhao, Research on Advanced Treatment of Heavy Metal Wastewater in Non-ferrous Metal Mine by ComplexationUltrafiltration Coupling Process, Hebei University of Engineering, Handan, China, 2014.

[31] Z. Huang, Study on In-Situ Treatment of Heavy Metal Ions in Acid Mine Water by Osmotic Reaction Bed Immobilized Sulfate-Reducing Bacteria and $\mathrm{Fe}-\mathrm{C}$, Anhui University of Engineering, Hefei, China, 2013.

[32] J. X. Chen and H. H. Li, "Research progress in treatment of heavy metal wastewater by ion exchange resin," Guangzhou Chemical Industry, vol. 41, no. 9, pp. 44-45, 2013. 